\title{
ESTÉTICA “DESDE ARRIBA" Y ESTÉTICA "DESDE ABAJO"
}

\author{
P O R

\section{MIGUEL B UENO}

T Ta de las deficiencias que se constatan en la filosofía -diriamos mejor, en la cultura toda- es la falta de una conciencia radical de la proyección que debe tener en la vida; el apartamiento que tradicionalmente se ha considerado en la filosofia no corresponde por esencia ni derecho a esta disciplina, y depende directamente de la vitalidad con que se promueva el acercamiento de los hechos reales, actuando como guía de orientación para el progreso de la vida espiritual.

La susodicha deficiencia tradúcese, en la disciplina estética, sobre el apartado cultural que le corresponde, o sea el arte. Origina el problema de construirla, bien mediante especulaciones puras o en la inmediatez de la experiencia, y crea de este modo las que se han llamado "estética desde arriba" y "estética desde abajo", significando el entronque al plano superior de la reflexión pura y la raigambre en la masa inagotablemente fecunda de los hechos artísticos. La distinción es procedente y no habria nada que objetarle si no fuera porque se ha querido ver en ella un injustificable antagonismo, suscitado por la incomprensión de la dualidad metódica que por modo natural se presenta en toda la filosofía, mediante la correlación valor-cultura que corresponde al pensamiento puro y a la actividad concreta. El interés que reviste comentar y justificar la dualidad estética "desde arriba" y "desde abajo" es la coordinación polar que rige al pensamiento estético y da valor a sus conclusiones, pero a condición de que ambos polos sean 
debidamente distinguidos y se mantenga su significación respectiva, y al mismo tiempo su unidad, garantizando la ascensión al plano explicativo de la teoría y el descenso a la concreción fáctica, donde se verifica la validez de las teorías. Con ello se retrae la cuestión del problema y método en la estética, que llevará espontáneamente a comprender el sentido de la dualidad precitada. Así defínese un asunto que, sin ser una investigación estética -es decir, un estudio valorativo del arteinvolucra uno de los temas que deben resolverse de principio para tal suerte de reflexión, so pena de dirigirla por un camino equivocado y frustrar el sentido autónomo en la teorfa filosófica de lo bello.

Mucho se ha discutido sobre esto, pues el planteamiento del método se complica con toda la filosofía y, por reflejo, con la cultura en general, de suerte que el problema del arte queda vinculado al de la ciencia, del derecho, de la lingiústica, etcétera, y al relacionarse con el panorama total de la cultura, la estética deja de ser un estudio especializado para constituirse en rama orgánica del saber humano. Por virtud de esta relación, el esteta se convierte en filósofo, y el artista incluye en su agenda el clásico problema de formar un concepto del mundo y de la vida.

Por todo ello, la reflexión metódica sobre el arte adquiere importancia singular en la estética y fuera de ella; tiende a fundamentar el trabajo del arte y ofrecer el nexo que lo emparenta con el resto de la vida consciente. No es de extrañar que numerosas discusiones se hayan suscitado en torno al método, pues en ellas se refleja la inquietud intelectual del hombre y su anhelo de llegar a un punto que le haga dominar el panorama del espiritu, partiendo de la vocación y dedicación al arte. Asf, la reflexión metódica tiene dos aspectos: el primero se refiere al método en la estética; el segundo, a sus conexiones con todo el perímetro de la filosofia.

\section{$\mathbf{I}$}

Método significa, en general, la manera de hacer algo. En este sentido cualquier acto debería tener un método, pues todo se hace de algún modo, pero el concepto filosófico del método se aplica exclusivamente a los actos conscientes, esto es, a aquellos actos cuya finalidad y forma de verificación es sabida por quien los realiza.

Para que pueda hablarse propiamente de un método es necesario que su realización dependa de un plan, pues el método consiste en la 
facultad de ejecutar deliberadamente un acto. De acuerdo con ello, no puede haber un método ajeno a la conciencia, pues el método sólo se aplica a la producción de actos conscientes. No hay propiamente un método en los actos reflejos, inconscientes o puramente mecánicos de la vida, como pudieran ser el acto de la respiración o los reflejos emotivos, aunque también se verifiquen de algún modo $y$ de acuerdo con un cierto "método natural", ajeno al poder de la conciencia, de donde el "método natural" es completamente diverso del filosófico. Ahora bien, éste, además de ser consciente en su empleo, puede explicarse racionalmente; entonces no sólo habrá la conciencia de un método sino la autoconciencia del mismo.

Cuando interesa un conocimiento profundo de cierta actividad, debe trascender la ejecución de los actos para fundamentarlos racionalmente. Esta aclaración es de primordial importancia en la estética, pues implica la reflexión trascendental sobre el arte; supone la ejecución de los hechos artísticos y se refiere a ellos, pero no quiere producir obras, sino explicarlas objetivamente. Lo singular del caso es que una realidad tan procedente no suele tener gran acogida en el artista, que tiende casi siempre a limitarse a la actividad práctica, ya sea netamente artística -creadora-o bien artesanal -reproductora-, queriendo soslayar las cuestiones de fundamentación axiológica. De aquí ha venido la separación, incomprensible e injustificable, del arte y la estética, paralelamente al divorcio de artistas y filósofos, generando la llamada "estética desde arriba", que proviene del manto filosófico, y la "estética desde abajo", que cultiva predominantemente el crítico de arte y tal vez el artista mismo.

Es de notar que dicotomía semejante se antojaría grotesco suponer en otros campos; no concebimos, por ejemplo, una "lógica desde arriba" y una "lógica desde abajo". El hecho de que se produzca en el arte y la estética, le pone en grave predicamento al sostener gelificadamente una dualidad que sólo resultaría justificable como provisional y direccional, en el seno de la unidad primigenia y metódica, mas nunca como dualidad radical y antagónica, según la han presentado. Por lo demás, resulta fácil rescatar a la "estética desde arriba" de su anonimato empírico, así como a la "estética desde abajo" de su anomia axiológica, mostrando en cada caso la necesidad de una complementación integral; para la primera, su proyección en la experiencia, y para la segunda, su orientación a la esfera ideal del valor.

Hay que afirmar, ante todo, la distinción entre el acto y la conciencia del acto, pues la actividad artística suele quedar como un que- 
hacer cotidiano que no requiere la conciencia y ni autoconciencia del método. Considerando que el arte es un particular modo de expresión, se le puede ejemplificar en el caso del lenguaje. En medio de su aparente espontaneidad, se requieren varios años de estudiar y practicar un idioma para dominarlo completamente. A veces, aunque se le hable con toda corrección, se ignora su gramática; ésta es la que aporta la conciencia lógica en el acto de hablar y parecerla que dicha reflexión está de sobra, puesto que se puede practicar un idioma sin haber estudiado su gramática. Esta clase de opiniones suelen verterse al caso del arte, pero son verdad hasta cierto punto, pues numerosos aspectos del lenguaje sólo pueden penetrarse mediante el conocimiento de la gramática. Una parte de la misma se aprenderá empíricamente y aun se practicará con toda corrección, como sucede a cada momento; el empirismo es factible en la práctica de ciertas actividades entre las que se cuentan principalmente las intuitivas, sobresaliendo, en primer término, la artistica, como una derivación de la expresividad en general.

Pero el hecho del empirismo no contiene implícita su justificación y toda forma expresiva deberá contener su fundamento racional, para lo cual se requieren las bases teóricas que implica el sistema de la estética. El arte mismo, con todo y su empírica intuitividad, reclama la conciencia y aun la autoconciencia de los hechos; el artista produce obras y para ello debe conocer la técnica del arte que profesa. Muchos estudios y larga práctica se requieren para dominarlo, de manera que a la base de su actividad se halla el conocimiento y la facultad de ejecutarlo. Pero así como el hombre asimila de un modo práctico la estructura del lenguaje, sin conocer explícitamente las reglas gramaticales, también el artista puede aprender un arte $y$ desplegar su facultad intuitiva sin necesidad de una profunda reflexión estética. Esto es lo que podríamos llamar la "práctica espontánea del arte".

Cuando el artista pregunta por el método y el valor de su facultad intuitiva, se convierte en psicólogo o crítico de arte, es un hombre que rescata del plano práctico a la ejecución para llevarla a una perspectiva superior que le permite apreciar panorámicamente lo que sucede en la experiencia. El pintor, a la vez que pintar, piensa en la pintura; un músico, además de componer, se pregunta cuál es el valor de sus composiciones. Ya no se trata entonces de la mera práctica artística, sino de la conciencia y autoconciencia de esta actividad. 
Tener conciencia del arte puede no ser un requisito indispensable para el buen artista; hay artistas natos en quienes florece una espléndida facultad creativa sin necesidad de la conciencia teórica; ello se debe al carácter intuitivo del arte. Pero no se considerará a la reflexión axiológica como inútil, ya que, por lo contrario, reporta grandes beneficios a la cultura artística. El primero de ellos es la objetividad del valor y la determinación de una norma directriz para la obra, el esclarecimiento objetivo del arte y la posibilidad de razonar sobre él, así como enseñarlo y hacer un patrimonio que pueda transmitirse en las generaciones, al alcance de toda la humanidad, lo cual sería imposible si el arte no fuera traído a una clara conciencia de sí mismo; inclusive el aprendizaje resultaría deleznable sin la meditación que expone de modo racional su contenido, pues no se podrían comprender las bases del oficio sin el guión pedagógico desde el cual se elaboran los planes de estudio y sistema de trabajo en las "academias" que requiere practicar antes de acometer una gesta propia. Ahora bien, el material de aprendizaje ha sido elaborado por pedagogos que, en cuanto tales, no son propiamente artistas, sino teóricos del arte.

\section{II}

Esta consideración se relaciona estrechamente con el problema direccional de la estética "desde arriba" y "desde abajo" en la medida que la vida del artista deberfa desenvolverse por un vasto sistema de conocimientos que principia en el desempeño del oficio y atraviesa una serie de planos críticos hasta llegar a la cima constituida por la reflexión axiológica e historiológica, donde se localiza el valor estilístico de la obra y su sentido histórico, que otorgan el criterio supremo del arte. La serie de planos reflexivos son, ni más ni menos, que las etapas del camino cuya ascensión describe la "estética desde abajo", hasta llegar al punto de culminación desde el cual forzosamente se descenderá en la "estética desde arriba". La tesis concluyente es que el conocimiento y el recorrido de ambas etapas promueve la unidad estética en el doble sentido que reporta la polaridad de referencia, con un ciclo que denota la frecuencia de evolución.

La falta de base teórica en el artista llega en su extremo a una desviación como es la artesanía, caracterizada por su falta de penetración analítica en el desempeño de la faena. La "estética desde abajo" llega a emparentarse con una especie de artesanía filosófica, pues radi- 
calmente "desde abajo" no puede ser la estética, faltándole las ideas que vienen "desde arriba", con lo cual revierte obligadamente al mundo de los valores. El crítico de arte se dedica afanosamente a visitar exposiciones en su afán de cumplir tal vez con alguna crónica periodística; llega a convertirse en un artesano de la crítica como máximo realizador de la "estética desde abajo". En términos generales, artesanía es ejecución y repetición de trabajos; depende de una facultad como la habilidad que, desde luego, tiene por base una cierta sensibilidad intuitiva, pero descansa fundamentalmente en la agudeza reproductora del artesano.

El arte propiamente dicho es, por el contrario, una faena de invención y originalidad, que no depende exclusivamente de la habilidad -aunque la reclama- sino del genio creador; esta última es la facultad más rara y al mismo tiempo la más fecunda del artista, quien debe poseer, además, las dotes del artesano, incluyendo la habilidad manual; pero el trasfondo humano del arte radica en el genio y la originalidad de creación. Ahora bien, esta originalidad depende en gran medida del conocimiento sobre las formas y el contenido de una verdadera "estética desde abajo". El hecho de la creación no es ningún acto fortuito, sino el fruto de una larga meditación que, unida a la continua práctica del arte, llega a concluir en la creación de obras originales. Nunca el genio ha brotado por generación espontánea, sino a consecuencia de la evolución que rige todo el curso de la vida. Artesanía es ejecución imitativa, como lo es también la audición y práctica de un lenguaje cuya gramática se desconoce. En el verdadero arte se da la creación, pero requiere del acto reflexivo que lo rescata del nivel artesanal para elevarlo, en alas de una explicación racional, hasta el plano de lo consciente y lo autoconsciente. Con una semejante "estética desde arriba" puede concebirse la innovación y la genialidad artística, derivando de una profunda incursión en el mundo de las relaciones entre la forma y el contenido, que otorgan valor a la creación.

Ahora bien, ¿qué relación guardan el ejercicio y la conciencia del arte, con respecto a la estética? Para aclararlo baste recordar esta distinción: mientras no se rebase el nivel artesanal, el saber es predominantemente mecánico y de imitación; cuando al ejercicio acompaña la reflexión axiológica y genética de la obra, se produce otro género de conocimientos que integran el saber estético, o sea la filosofia del arte. Si además de este conocimiento se verifica otro que explique to que es el saber estético, se tendrá una tercera clase de reflexión, auto- 
consciente o trascendental, que pone de relieve el doble método de la estética. Para llegar a la suprema comprensión metódica del "arriba" y del "abajo" hay que captar los planos anteriores en el saber en el arte, distinguiendo tres clases de conocimiento: uno primario, que corresponde a la actividad artesanal, otro consciente, que atañe a la estética, y un tercero, abstracto y culminante, que pertenece a la conciencia metódica. Este último, desde su plano superior, explica el doble mecanismo del saber estético.

Para la realización de una obra y la comprensión de su valor hay que superar la artesanía de la imitación para elevarse a las categorias formales y estilisticas. Así se plantean las condiciones que debe llenar una obra para ser bella, esto es, para exponer un valor positivo. La estética se encarga de estipular dichas condiciones en función del valor; pero al mismo tiempo se pregunta cómo ha de llegar al más amplio conocimiento, el camino o método que ha de seguir para la resolución del problema. Paralelamente, admite la cuestión de cuál será el aspecto del arte que deba tomarse como problema estético. Ambos, método y problema, están indisolublemente ligados, de suerte que nada puede aclararse sobre el primero sin saber en qué consiste el segundo, ni se llegará a una conclusión sobre cuestión alguna sin el empleo de un método adecuado. Por ello se deben tratar simultáneamente el problema y el método en la estética; la indicación de éste contiene implícita la solución de aquél, y recíprocamente, el señalamiento del problema es un indice para el método que deba procurar la solución. En la llamada "estética desde arriba" el problema gira en torno al debate ideológico, relegando a un segundo término el encuentro con las obras; el método se desenvuelve en el plano de teb́rica racionalidad que, en su extremo, llega al nefasto abstracionismo donde se discuten teorías sin tener en cuenta el objeto respectivo, lo cual ha sido justamente criticado por los partidarios de la "estética desde abajo", que generalmente son artistas y criticos de arte con un contacto directo en el fenómeno creativo. Tales partidarios suelen mantenerse en la indeclinable fragmentación de la empirie, que tiene igualmente diversos matices de expresión, desde el que trata el problema de la crítica en un plano de altura y resuelve la cuestión del valor, hasta la mera crónica que se desenvuelve en una revista de impresiones, desmereciendo la unidad orgánica de la reflexión; llega al subjetivismo, como sucede en los debates abstraccionistas, pues la motivación no gira en torno a ideas, sino a impresiones. 
Este hecho no sólo ha surgido en el problema estético, sino en toda la filosofía, concluyendo en el "ensayismo" que tiene ribetes deleznables de improvisación. Es casi innecesario, a estas alturas, afirmar que ninguna de las dos "estéticas" es dueña exclusiva del método para filosofar sobre el arte, el cual se integra por dos sentidos, el ascenden. te y el descendente, correspondiendo a la doble dimensionalidad de la filosofia, la empírica y la ideal.

\section{III}

El saber estético culmina en la comprensión del método. El problema ha quedado circunscrito al valor del arte, a su contenido esencial, en la inteligencia de que además, y en torno a ella, existen otros aspectos periféricos, de los que se ocupan otras ciencias; al establecer claramente el tema de la estética se evita confundirlo con el de dichas ciencias. Lo mismo puede afirmarse del método; al caracterizar el de la investigación estética se evita confundirlo con el de aquéllas. Esta clarificación inicial de métodos y problemas es condición indispensable para que la ciencia del arte llegue a un feliz desarrollo, no obstante lo cual ha registrado un gran número de confusiones, aun en doctrinas de primera importancia. En ello interviene también la referida dualidad estética, en la cual se han presentado dichas confusiones; en la "estética desde arriba" se registran principalmente confusiones psicologistas, y de ahí que un buen número de teorias estéticas -por ende, pretendidamente filosóficas- no son en realidad más que acotaciones psicológicas que valen en su propio ámbito, pero carecen de autoridad para dirimir la validez objetiva de las obras. Por su parte, la que va "desde abajo" registra confusiones de carácter naturalista, en el sentido de la ciencia físico-matemática, o bien histórico-sociológica, que ha tenido importantes intervenciones en el conocimiento del arte, aportando datos de gran valía para su captación científica. Por ello, buena parte de las reglas de la estética empírica corresponden a una física, matemática, psicológica o historia del arte.

El hecho de fijar al valor "belleza" como objeto de la estética produce la eliminación de los asuntos periféricos, así como también las confusiones que han surgido en torno a la obra, por cuya superficie evolucionan las "ciencias del arte". La consideración metódica en la estética lleva a concluir que el único enfoque subsistente frente a di- 
chas ciencias es el que adopta al valor de la obra en cuanto belleza y originalidad. Cualquier otro problema encontrará una ciencia particular capacitada para estudiarlo.

Pero si el valor de las obras constituye un solo aspecto -aunque el central- del arte, podría creerse que el arte mismo es una reunión anárquica, o por lo menos ajerarquizada, de temas y que la cuestión del valor sería una de tantas en la problemática sobre la creación artística. Pero el valor no es simplemente uno de los aspectos del arte, sino el principal; el valor se resuelve, en último término, como la esencia del arte mismo, como la función unitaria que permanece constante en medio de la diversidad de aspectos artísticos.

Prueba de ello es que al hablar de "sociología del arte", "física del arte", "psicología del arte", "historia del arte", etcétera, se emplea el concepto común de "arte", como referencia básica del problema; dicho concepto reporta la esencia por cuya comunidad funcional se constituyen las condiciones conforme a las que una obra llega a ser bella y al mismo tiempo original. Condiciones que equivalen a normas generales o requisitos de ejecución. Afirmando que la belleza no debe ser efecto de imitación (en cuyo caso la obra será producto de artesanía) se llega al acto creador y original en el que radica lo más importante del arte. El problema se extiende a una serie de cuestiones derivadas que lo resuelven conjuntamente como teorfa general de la belleza artística. El propósito más importante de la estética es llegar a una conclusión que establezca las condiciones para que una obra posea auténtico valor.

Para ello es indispensable partir del arte mismo, de la consideración múltiple que brindan sus obras, y remontarse a una generalidad que no está reñida con la realidad artística, sino al contrario, queda explicada en su propia esencia y sin alterar su interna estructura. Hay que mantener a la investigación en un camino que puede $y$ debe recorrerse en dos sentidos, cuyos extremos son el conjunto de las obras y la conclusión general buscada. El primer sentido parte de aquéllas para llegar a la conclusión general, y el segundo parte de ésta para verificarse en las obras de arte; sin el primero no existiría propiamente una investigación estética, puesto que ella es quien procura la norma general de la belleza y sin el segundo se caería irremisiblemente en la especulación, como sucede en otra clase de teorías que no tienen apoyo dónde verificarse. Ir de lo particular a lo general y volver de lo general a lo particular; he aquí el método en cualquiera investigación. 
Esta dualidad metódica es universal; su aplicación al arte determina al método estético, y de ahí derivan otros conceptos metódicos, a saber:

a) El valor del arte consiste en la belleza y originalidad de las obras.

b) El establecimiento de las condiciones axiológicas implica el tránsito de las obras a la teoría, y viceversa.

Este repetido ir y venir de lo particular a lo general es un tránsito dialéctico. En términos generales, dialéctica es el encuentro de una primera idea o tesis, con una segunda idea, antítesis o heterotesis, para producir una tercera resultante, conocida como síntesis. Cada una de ellas es una fase de la dialéctica y su existencia es necesaria para llegar a la formulación de una norma aplicable al arte; es una idea por la cual se pretende explicar el valor de las obras. La primera idea constituye la tesis, pero como no es perfecta, hallará contradicciones en la realidad, que viene a constituirse como antítesis. Se hará entonces una meditación para resolverla y de ah́́ surgirá otra idea mejor que la primera, fruto y conciliación del primer choque dialéctico, generador de la síntesis.

Asf debe llegarse a la esencia y el valor del arte; se partirá de las obras para formular una idea y verificarla en la realidad, lo que no se logra de inmediato $y$, hablando en términos rigurosos, no llega a realizarse nunca a la perfección. El ciclo tesis-antítesis-síntesis debe repetirse continuamente, afirmando la estructura dialéctica del método. Por su naturaleza progresiva, la dialéctica no existe solo para la estética, sino para cualquier ciencia, cuya verdad no se obtiene de golpe, sino en inacabable desarrollo. De ahí que el ciclo metódico dialéctico se repita constantemente en una infinita evolución.

Captando la naturaleza del método se llega a la conclusión de que la verdad es siempre imperfecta $y$, hasta cierto punto, provisional y transitoria. Al formular una tesis, al encontrar su heterotesis y resolver la contradicción en una síntesis, es de tener en cuenta que no se trata de ideas perfectas ni definitivamente asentadas, sino de tesis que tienen un carácter perfectible. De ahí que los momentos del mótodo -tesis, antitesis, y sintesis- no sean mas que hipótesis de trabajo, esto es, suposiciones que desean explicar un problema dinámico sin resolverlo a la perfección. En caso que fueran soluciones perfectas dejarían de ser hipótesis para convertirse en teorías absolutas; pero ello no sucede en la realidad, que rectifica continuamente sus verdades y obtiene la mejor solución posible, nunca la respuesta definitiva. 
Lo propio acontece en el arte. El hecho de que continuamente se produzcan polémicas expresa que no se trata de una cuestión fácilmente soluble, sino al contrario, de un problema extraordinariamente complejo. Todo lo que sobre él se haya dicho hasta ahora, no pasa de ser una aproximación que se ve en la necesidad de nuevos y más finos retoques, procediendo a recorrer el viaje de ida y vuelta que tiene como extremos a la producción artística y al mundo de las ideas. Que no se tenga una conclusión definitiva, origina la continua aparición de nuevas ideas, esto es, de nuevas hipótesis. El día que la estética no fuera hipótesis o verdad provisional, sino verdad definitiva, se rubricaría la investigación y se clausurarían todos los centros que inquieren sobre la esencia y el concepto del arte.

La forma clásica de la dialéctica es el método por cuya virtud se relacionan los términos contrarios, lo cual está implícito en la formación de la tesis, de su contraria antítesis, y de su reaunión en la síntesis. La expresión estética del método suele darse como participación de dos términos contrarios: lo objetivo y lo subjetivo, en la creación y explicación de la obra, lo cual se relaciona con el problema de fondo en la medida que la "estética desde arriba" suele exponer una tendencia subjetiva, en tanto que la "estética desde abajo" obedece a una proyección objetivista.

\section{IV}

Objetivo es lo propio del objeto, mientras que subjetivo es lo característico del sujeto. En el conocimiento estético interviene lo objetivo desde el momento que en el objeto -obra- proporciona el tema de estudio; también interviene lo subjetivo puesto que el sujeto realiza la inquisición. Ahora bien, lo objetivo no llega nunca a identificarse con lo subjetivo $y$, sin embargo, hay que considerar que el objeto debe asimilarse al sujeto y que lo subjetivo pueda resolverse en el objeto. El hecho de que objeto y sujeto sean distintos no tendria mayor importancia si no fuera porque la dialéctica estética pretende explicar al arte identificando en cierto modo ambos términos, con lo cual se establece inmediatamente una contradicción; para resolverla se imponen nuevas reflexiones que tiendan a aproximar, tanto como posible, los términos objetivos y subjetivos. En la relatividad de la aproximación se implica la indefinida permanencia del método dialéctico. 
Los conceptos de objetividad y subjetividad revisten capital impor. tancia tratándose de cuestiones estéticas, principalmente metódicas. Aclaremos que el problema se refiere a lo objetivo y lo subjetivo de la verdad estética, es decir, de la presunta explicación del arte, mas no del arte mismo, sobre el cual también se discute la objetividad o subjetividad de la creación. En otras palabras, no se trata de si el arte es objetivo o subjetivo, sino del conocimiento en el cual consiste la estética; si expone una mera opinión del sujeto pensante -esteta, crítico, historiador o) un conocimiento objetivamente fundado.

Aplicada la dialéctica a la estética, no se requieren muchas palabras para indicar que el conocimiento del arte oscila entre los polos de esta correlación; participa de lo subjetivo puesto que se origina en un sujeto, pero tiende a resolverse en lo objetivo al aceptar como criterio de verificación a la realidad de la obra. En esta comunidad de lo subjetivo y lo objetivo nace la dialéctica del método; su continua evolución tiende a resolverse funcionalmente para satisfacer la veracidad progresiva impuesta como norma del tratadismo estético, aplicando el criterio de valor a la muchedumbre de obras y vivencias que forman el mundo del arte.

Otro problema, conectado con el anterior, es el que se refiere a la objetividad y subjetividad del arte mismo, englobado el valor que realiza; pero éste no es un tema de carácter metódico trascendental, sino el punto básico de la doctrina estética propiamente dicha. Los términos de subjetividad y objetividad en el arte pueden substituirse por los conceptos de gusto y valor, respectivamente. Al dar una opinión sobre determinada obra, lo que se hace en realidad es expresar un sentimiento de gusto, ya sea de agrado o desagrado; referirse a ella es para encontrar algo propio que la haga substituir independiente de cualquier opinión personal. Ese algo, su valor, es la belleza contenida en el arte.

La tendencia general de las opiniones depende de que dicha obra guste o no a quien la perciba. Cuando además de expresar agrado o desagrado, se hace depender al valor estrictamente de la impresión original, se comete el error heterónomo del subjetivismo, que, por desgracia, es demasiado frecuente aun en los ambientes de la crítica profesional. Para evitarlo hay que dar forma objetiva al juicio de la obra, no haciéndola depender de la impresionable subjetividad. Pero esta no es una actitud de facto, puesto que exige no limitarse a dar una opinión, sino el por qué de la obra misma. Si queremos entender el gusto de algo, habrá que saber lo que gusta en general, pues sólo conociendo 
genéricamente la cualidad entitativa del gusto se llega al conocimiento de por qué una o varias cosas han gustado, y de ahí se obtiene la teoría general del gusto, con aplicación a cada caso singular. Este es el complejo problema de la psicologia del arte.

Con lo anterior, tenemos sucintamente explicada la génesis de la "estética desde arriba" y la "estética desde abajo", que son las vertientes de la única y verdadera estética, o sea la doctrina axiológica del arte. Con ello creemos cumplir el requisito de unidad, impostergable en cualquier multiplicidad predicativa; al mismo tiempo consideramos que la dirección de cada vertiente estará plenamente justificada con la atribución que le corresponde: a la primera, el discernimiento de las teorías, y a la segunda, el conocimiento de las obras. Ninguna puede en sí misma colmar sus propósitos si se considera reñida con la otra, y por ello es indispensable contribuir a la formulación de un criterio unívoco y conducente a la interrelación dialéctica que afirme su continuo progreso. A partir de esta conclusión el problema del gusto queda relativizado a la valoración de la belleza, considerando que el sentido general del método haya sido resuelto.

Estableciendo lo que puede gustar en general, se dirá lo que tiene el arte para gustar de él. La única respuesta es que las obras gustan porque contienen belleza, o si se prefiere, porque son bellas. De este modo se libera a la cuestión estética del individualismo subjetivo del gusto para proyectarla sobre el valor; este se objetiva y no queda reducido únicamente a la impresión que origina. La consideración en torno al valor consiste en partir de la obra para llegar a la teoría general del gusto, y de ahí volver a la obra para verificar la teoría del valor; este es el doble tránsito de la reflexión estética.

Hay una contradicción entre el criterio del valor y la sensación subjetiva, contradicción que se refleja constantemente en el hecho de que una obra puede disgustar al gran público, a pesar de que objetivamente posea un gran valor $y$, por ello, una gran belleza. No todas las obras valen en la medida que gustan ni gustan en la medida que valen. Este es un hecho universal en la experiencia estética del hombre.

Por la misma contradicción surge otro motivo que justifica a la dialéctica y la hace necesaria; la formularemos del siguiente modo: deben gustar las obras en la justa medida de su valor; esto equivale a identificar funcionalmente al valor con el gusto, y aunque tal identificación es muy difícil de lograr en la práctica, la intensificación educativa ha permitido un grado apreciable en su verificación. Es frecuente 
el caso de obras con un gran mérito intrínseco que fracasaron al presentarse, y que después se justificaron como realizaciones auténticas. Recíprocamente, obras de muy poco valor, que causaron al principio una magnífica impresión, fueron después relegadas al lugar que les correspondía. Parece que el tiempo repercute favorablemente en la comprensión del público y éste acaba dejándose llevar por un mejor criterio objetivo; el valor influye en el gusto por la conciencia del valor, aunque en un principio aquél no complaciera del todo. Gracias a ello se han abierto paso las tendencias nuevas, y fundamentalmente las revolucionarias, en todo el campo del arte. La investigación estética no puede menos de tener en cuenta este hecho para la adecuada estimación de sus propias conclusiones, sobre todo en lo que se refiere a trabajos de carácter histórico.

Aclaremos, finalmente, que el problema y el método en la estética forman uno solo de lo que presenta la filosofia; indagar en qué consiste el valor del arte encuentra paralelo en el valor de la ciencia, de la moralidad, de la religión, en el problema de toda la cultura, que desenvuelve en el carril más amplio a la problemática de la existen. cia. Su resolución corre a cargo de la filosofía que es, por excelencia, la encargada de resolver las cuestiones de valor. La "filosofía general" aborda los problemas genéricos y las disquisiciones metódicas, que tienden a despejar el camino de la reflexión, incluyendo las observaciones críticas que previenen las desviaciones heterónomas; la "filosofía especial" se ramifica en las diversas disciplinas que se ocupan de cada problema de valor.

La estética es una rama de la filosofía; hacer estética es tanto como filosofar sobre el arte. La analogía de problema y método en cada uno de los valores se refleja en la analogía de los desarrollos que se observan en las disciplinas filosóficas. Hablando en rigor, hay solamente un problema y un método: el del valor, que es necesario resolver en dos sentidos, de lo particular a lo general y de lo general a lo particular, de las ideas a los hechos y de los hechos a las ideas. La estética debe llegar a la realidad artística y tomar nota de sus incontables hechos y obras, formular hipótesis que expliquen su valor y verificarlas en el terreno de la experiencia, comprobando su validez no sólo para las ya realizadas, sino aventurándolas para las que hayan de producirse en el futuro. Sólo de este modo puede alcanzar la filosofá, y con ella, la estética, el rango de universalidad que corresponde a toda verdadera ciencia. 